\title{
Profile of Cardiovascular Risk Factors in Nigerians with Stroke
}

\author{
Jamila Ado Yau' ${ }^{1}$, Kamilu Musa Karaye ${ }^{2}$, Basil N. Okeahialam³ \\ ${ }^{1}$ Public Health and Diagnostic Institute, Northwest University, Kano State, Nigeria \\ ${ }^{2}$ Bayero University Kano/Aminu Kano Teaching Hospital, Kano State, Nigeria \\ ${ }^{3}$ Jos University Teaching Hospital, Plateau State, Nigeria \\ Email: jamilayau@yahoo.com
}

How to cite this paper: Yau, J.A., Karaye, K.M. and Okeahialam, B.N. (2016) Profile of Cardiovascular Risk Factors in Nigerians with Stroke. World Journal of Cardiovascular Surgery, 6, 125-137.

http://dx.doi.org/10.4236/wjcs.2016.610020

Received: September 18, 2016

Accepted: October 28, 2016

Published: October 31, 2016

Copyright $\odot 2016$ by authors and Scientific Research Publishing Inc. This work is licensed under the Creative Commons Attribution International License (CC BY 4.0).

http://creativecommons.org/licenses/by/4.0/

\begin{abstract}
Background: There is paucity of data on cardiovascular disease (CVD) risk factors among stroke patients in our population. This study aimed at assessing CVD risk factors amongst stroke patients compared with apparently healthy controls. Methods: This was a case-control study conducted at Aminu Kano Teaching Hospital Kano. One hundred stroke subjects were consecutively recruited and compared with 100 age and sex matched controls. The CVD risk factors assessed were hypertension, diabetes mellitus, dyslipidemia, obesity, cigarette smoking, alcohol consumption, socioeconomic status (SES), increased age, male gender and Human Immunodeficiency Virus (HIV) status. Results: Mean age was $56.4 \pm 15.8$ years for cases and $54.5 \pm 15.4$ years for controls $(p=0.39)$, and $53 \%$ of the former and $52 \%$ of the latter were males $(p=0.887)$. The most prevalent CVD risk factor was hypertension, found in $71 \%$ of cases and $42 \%$ of the controls, $(p=0.01)$. All heart diseases were found in $70 \%$ of cases and $21 \%$ of controls $(\mathrm{p}<0.001)$, and hypertensive heart disease (HHD) was the commonest, found in $55 \%$ of cases and $18 \%$ of controls $(\mathrm{p}<0.001)$. Dyslipidemia was found in $53 \%$ of cases and $37 \%$ of the controls $(\mathrm{p}=0.023)$, diabetes mellitus/hyperglycemia in $23 \%$ of the cases and $6 \%$ of the controls $(\mathrm{p}=0.01)$, history of transient ischemic attack (TIA) in $19 \%$ of cases and $1 \%$ of the controls $(\mathrm{p}=0.01)$, while atrial fibrillation was found in 9\% of cases only. Other risk factors were uncommon. Conclusion: The most frequent CVD risk factors among Nigerians with stroke were systemic hypertension, heart diseases, male sex and dyslipidemia, while HIV and other risk factors were uncommon. Thus medical attention and public enlightenment should focus on the common ones as detected in this study.
\end{abstract}

\section{Keywords}

Stroke, Risk Factors, Hypertension, Nigerians 


\section{Introduction}

Global burden of stroke is high, inclusive of its increasing incidence, mortality, disability adjusted life years (DALYs), and economic impact, particularly in low and middle-income countries (LMIC) [1]. Stroke is the second leading cause of death worldwide after ischemic heart disease (IHD) accounting for 6.7 million deaths (12\% of total deaths) in 2012 [2]. Globally, about 16 million new cases of stroke and 62 million stroke survivors were estimated in 2005, and this is expected to increase to over 23 million new stroke cases and 7.8 million stroke deaths by 2030 in the absence of significant global public health response [3] [4].

The Prevalence and pattern of CVD is distinctly different in Sub-Saharan Africa compared with the rest of the world. Among the CVDs, there is relative increase in occurrence of atrial fibrillation in addition to other traditional risk factors [5]. Given the etiologic role of atrial fibrillation for stroke, significant additional surveillance is needed and more detailed analysis of the mechanisms of atrial fibrillation is warranted [6]. Other emerging risk factors such as HIV infection are shown to be relevant to the etiology of CVDs including stroke. Knowledge on the prevalence of these risk factors will aid in health care planning as well as serve as base line for further surveys.

The rising incidence of stroke might not be unrelated to the prevalence of cardiovascular risk factors, which has not been well studied in Kano, Nigeria, a city that seems to relatively be at an advanced stage of epidemiologic transition [7]. We therefore aimed to study the prevalence of CVD risk factors in adult stroke patients attending a tertiary level hospital, in comparison to controls without stroke, in Kano, Nigeria.

\section{Methodology}

This was a case-control study conducted over a period of twenty weeks (August $15^{\text {th }}$ to December $15^{\text {th }}$ 2011) at Aminu Kano Teaching Hospital (AKTH).

Before the commencement of the study, the study protocol was approved by the ethics committee of AKTH, Kano. Informed written consent was obtained from all subjects, and for those who could not sign a thumb print was taken or consent was signed by a next of kin. The HELSINKI declaration on investigations of human subjects was respected [8].

Patients with stroke admitted into the emergency and the medical wards of the hospital satisfying the inclusion criteria were recruited consecutively until the sample size was obtained. Control group was formed by individuals without stroke presenting to the General Out-Patients (GOP) Clinic with minor ailments and were investigated in a similar manner as were the cases. The 2 groups were matched for age and gender.

Sample size was estimated using the formula: $N=Z^{2} \mathrm{P}(1-\mathrm{P}) / \mathrm{d}^{2}$

where $\mathrm{N}=$ minimum sample size,

$\mathrm{Z}=$ standard deviation $=1.96$ (at $95 \%$ confidence interval),

$\mathrm{D}=$ sample error $=5 \%$,

$\mathrm{P}=$ prevalence of HIV among stroke patients $=3.4 \%{ }^{9}$, HIV infection was used to es- 
timate the minimum sample size because it was the least common risk factor for stroke in a recent study by Ezeala et al. [9].

Inclusion criteria for the cases were: admission to the medical wards or the emergency unit with stroke as defined by the World Health Organization (WHO) criteria, and presenting within the first seven days of the event; age of 18 years and above, and giving informed consent to participate in the study [10]. Patients less than 18 years of age, or those who did not have stroke, declined consent or who presented after the first seven days of stroke were excluded from the study.

The inclusion criteria for the control group were-subjects who presented to GOP with minor ailments but who have never suffered a stroke, aged 18 years and above, and who gave consent to participate in the study. GOP subjects less than 18 years, or who have had a stroke or who declined consent were excluded.

The assessed risk factors were: age, male gender; hypertension; diabetes mellitus (DM); current tobacco smoking; heavy alcohol consumption; heart diseases such as hypertensive heart disease (HHD), atrial fibrillation (AF), valvular heart disease and cardiomyopathies, dyslipidaemia, sedentary life style and use of oral contraceptive pills (OCP) in women. HIV screening was included as it is considered an emerging risk factor for stroke [11].

\subsection{Stroke}

Stroke was defined according to the World Health Organization (WHO) clinical criteria as a "rapidly developing clinical syndrome of focal (or global in the case of subarachnoid haemorrhage) disturbance of cerebral function lasting longer than 24 hours (unless interrupted by surgery or death), presumably of vascular origin" [12].

Hypertension was defined according to the recommendation of WHO/International society of Hypertension (ISH), using the cutoffs of systolic blood pressure (SBP) of $\geq$ 140 and or diastolic blood pressure (DBP) of $\geq 90 \mathrm{mmHg}$ [13] or on antihypertensives prescribed by a physician. Diabetes Mellitus was defined as: Fasting plasma glucose of $\geq 7 \mathrm{mmols} / \mathrm{l}$ in an individual with typical symptoms of DM, or on at least 2 separate occasions if there were no such symptoms [14]; the plasma glucose $\geq 11.1 \mathrm{mmols} / 1$ two hours after a glucose tolerance test [14]; a previously diagnosed diabetic was considered as such even if glycemic control had been achieved. Hyperglycemia was defined as fasting plasma glucose $\geq 7.0 \mathrm{mmol} / \mathrm{l}$ post stroke in a patient without a previous history of DM [15]. Dyslipidemia was defined as the presence of fasting Total Cholesterol (TC) $>5.2 \mathrm{mmols} / \mathrm{l}(200 \mathrm{mg} / \mathrm{dl})$, low density lipoprotein $(\mathrm{LDLc})>3.38 \mathrm{mmols} / \mathrm{l}(130$ $\mathrm{mg} / \mathrm{dl}$ ), high density lipoprotein (HDLc) $<1.0 \mathrm{mmols} / 1(40 \mathrm{mg} / \mathrm{dl})$ in men and 1.2 $\mathrm{mmol} / \mathrm{l}(50 \mathrm{mg} / \mathrm{dl})$ in females or Triglycerides $>1.70 \mathrm{mmol} / \mathrm{l}(150 \mathrm{mg} / \mathrm{dl})$ [16]. Cigarette smoking was quantified as the average number of sticks of cigarette smoked per day for a specific duration. It was considered a risk factor if smoking was daily regardless of the dose. Obesity was defined as body mass index (BMI) $\geq 30 \mathrm{~kg} / \mathrm{m}^{2}{ }^{2}$ Waist Circumference was also recorded for the patients, and considered high if $>88 \mathrm{~cm}$ in females and $>102 \mathrm{~cm}$ in males. 


\subsection{Excessive Alcohol Ingestion}

Alcohol intake was considered excessive in males if $>21$ units/week and $>14$ units/week in females was consumed [17]. Increased age: defined as more than $55 \mathrm{yrs}$ in males and 65 yrs in females [12]. Gender: the two genders were recognized (male and female) according to what the subject claims. Sedentary life style: life style of individuals who do not engage in at least 20 minutes of light to moderate intensity exercise daily [7]. Low socioeconomic status: this was judged from the level of education, income or employment. It was defined as having monthly income of $<20,000$ Naira for single person, or $<25,000$ Naira for a couple and an additional 5000 Naira for each child. This was based on the local purchasing power of the Naira and the salary scale of the Kano state Government for civil servants [18]. Human immunodeficiency viral infection (HIV) was identified by the detection of HIV-specific antibodies in serum or plasma with the highly sensitive HIV-1/HIV-2 enzyme immunoassay (EIA) tests. Consent was obtained prior to HIV screening with pre and post test counseling. The patients that were eventually found to be HIV positive were referred for further workup and treatment at the appropriate clinics in AKTH. Heart diseases considered included HHDx, atrial fibrillation, cardiomyopathies, ischemic heart disease (IHD), and valvular heart diseases. These were diagnosed based on standard criteria, using history, physical examination, electrocardiography and echocardiography [19] [20]. ECG was done using Bionet Cardiocare EKG-2000 machine (made in South Korea) and echocardiographic machine used was ALOKA SSD-4000 (made in Germany) Machine and a 2.5 to $5.0 \mathrm{~Hz}$ linear array transducer.

A computerized tomography scan was done on patients who could afford its high cost. However, for those who couldn't afford the CT scan, stroke was sub-typed into ischemic and hemorrhagic types based on the WHO validated clinical criteria [10]. A diagnosis of ischemic stroke was made in the following circumstances: 1) when the stroke occurred in a state of relative inactivity, 2) absence of preceding headache. 3) absence of vomiting, 4) absence of post-stroke loss of consciousness, 5) presentation with mild to moderately elevated blood pressure as compared with severely elevated blood pressure for hemorrhagic stroke, and/or 6) a past history of transient ischemic attack(s) [10]. A diagnosis of hemorrhagic stroke was made in the presence of severely elevated BP and inverse of the above features [21].

Data were collected using a pre-tested semi-structured interviewer administered questionnaire which was administered by one of us YJA.

\subsection{Statistical Analysis.}

Data was collected from all the 200 subjects in data sheets, and then analyzed using SPSS (version 19.0). Chi-square, Fisher's exact probability, Student's $t$ - and MannWhitney $U$ tests were used to compare categorical and continuous variables as appropriate. $P$ value of $\leq 0.05$ was considered to be statistically significant.

\section{Results}

A total of 100 stroke patients were consecutively recruited into the study and compared 
with 100 age and sex matched controls.

The mean age for the cases was $56.4 \pm 15.8$ years and $54.5 \pm 15.4$ years for the controls $(\mathrm{p}=0.39$ ). Among cases, $53 \%$ were males and $47 \%$ were females, while in the control group $52 \%$ were males and $48 \%$ were females $(\mathrm{p}=0.887)$.

The profile of CVD risk factors among cases and controls is presented in Table 1. Hypertension was the commonest CVD risk factor present in $71 \%$ of the cases and $42 \%$ of the controls $(\mathrm{p}<0.001)$. The prevalence of low SES, family history of stroke or TIA, heart diseases, LVH based on ECG criteria, positive HIV status, atrial fibrillation, DM, hypertension and dyslipidemia were all higher among cases than controls $(\mathrm{p}<0.05)$. However, excess alcohol intake, atrial fibrillation and HIV were exclusively found in the stroke patients. The mean SBP was $152.26 \pm 31.50 \mathrm{mmHg}$ among the cases and $128.5 \pm$ $15.99 \mathrm{mmHg}$ among the control group $(\mathrm{p}<0.001)$, while the mean DBP for the cases and control was $93.38 \pm 20.13 \mathrm{mmHg}$ and $80.75 \pm 12.69 \mathrm{mmHg}$ respectively, $(\mathrm{p}<$ 0.001). The mean fasting blood sugar for the cases was $6.274 \pm 2.45 \mathrm{mmol} / \mathrm{L}$ and $4.6 \pm$ $1.3 \mathrm{mmol} / \mathrm{L}$ for the controls ( $\mathrm{p}$-value $<0.001$ ). The mean TC, LDL, HDL and TG for the cases were $5.16 \pm 1.07,2.9 \pm 0.91,1.26 \pm 0.43,1.21 \pm 0.52$ respectively, and $4.81 \pm 0.81$, $3.03 \pm 0.76,1.20 \pm 0.3,1.113 \pm 0.43$ for the control group (p-values $0.0081,0.33, \mathrm{p}$ $0.339, \mathrm{p}-0.18$ respectively).

Table 1. Profile of cardiovascular risk factors among cases and controls.

\begin{tabular}{|c|c|c|c|}
\hline Variable & Cases N (\%) & Controls $\mathrm{N}=(\%)$ & $\mathrm{p}$-value \\
\hline Male gender & $53(53 \%)$ & $52(52 \%)$ & 0.889 \\
\hline Increased age & $47(47 \%)$ & $44(44 \%)$ & 0.670 \\
\hline Cigarette smoking & $10(10 \%)$ & $9(9 \%)$ & 0.809 \\
\hline Excessive alcohol Intake & $5(5 \%)$ & $0(0 \%)$ & \\
\hline Sedentary life style & $82(82 \%)$ & $72(72 \%)$ & 0.090 \\
\hline Low SES & $64(64 \%)$ & $42(42 \%)$ & $<0.016$ \\
\hline Family history Of stroke & $14(14 \%)$ & $5(5 \%)$ & $<0.030$ \\
\hline Obesity & $15(17 \%)$ & $16(16 \%)$ & 0.790 \\
\hline History of TIA & $19(19 \%)$ & $1(1 \%)$ & $<0.001$ \\
\hline Heart disease & $70(70 \%)$ & $21(21 \%)$ & $<0.001$ \\
\hline $\mathrm{LVH}(\mathrm{ECG})$ & $34(34 \%)$ & $15(15 \%)$ & 0.002 \\
\hline HIV & $2(2 \%)$ & $0(0 \%)$ & \\
\hline Atrial fibrillation & $9(9 \%)$ & $0(0 \%)$ & \\
\hline Recreational Drugs & $2(2 \%)$ & $1(1 \%)$ & 0.560 \\
\hline $\mathrm{COCP}$ & $2(2 \%)$ & $4(4 \%)$ & 0.414 \\
\hline Diabetes mellitus & $23(23 \%)$ & $6(6 \%)$ & 0.010 \\
\hline Hypertension & $71(71 \%)$ & $42(42 \%)$ & 0.001 \\
\hline Dyslipidemia & $53(53 \%)$ & $37(37 \%)$ & 0.023 \\
\hline
\end{tabular}

Key: N, total number of subjects; ECG, electrocardiography; TIA, transient ischemic attack; LVH, left ventricular hypertrophy; HIV, human immunodeficiency virus; COCP, combined oral contraceptive pills; SES, Socioeconomic status. Values expressed as number with percentages in bracket. 
Among the heart diseases, HHD was the commonest, seen in $55 \%$ of the cases and $18 \%$ of the controls, $\mathrm{p}<0.0001$, followed by rheumatic valvular heart disease (RHD) in $8 \%$ of cases and $2 \%$ of controls ( $\mathrm{p}=0.052$ ), IHD in $6 \%$ of cases and $1 \%$ of the controls, $(\mathrm{p}=0.059)$, while Dilated cardiomyopathy (DCM) was present in $1 \%$ of the cases only. Echocardiography was done on all the cases and the controls.

\section{Discussion}

The present study assessed the prevalence of cardiovascular risk factors in stroke patients in comparison with controls. The most frequent risk factors for stroke in our study were systemic hypertension, heart diseases, male sex and dyslipidemia, while HIV and other risk factors were uncommon.

The results show that stroke occurred at a relatively young age (56.4 \pm 15.8$)$, which is in keeping with an earlier cross-sectional study in the same centre, and to previous reports from other centers in Nigeria [22] [23]. However this is at variance with studies from the western world, including a recent study in Portugal, in which a mean age of $73.2 \pm 8.7$ years among stroke patients was reported [24]. This may be a reflection of differences in life expectancy between the developed and developing world. As regards gender distribution, the present study did not find any significant difference between the 2 genders, in keeping with findings from a previous study [22]. Another study by Desalu et al. demonstrated a relative increase in stroke prevalence in females who were older than the male counterpart [25]. This was attributed to a greater life expectancy among the women, as $60.3 \%$ of those with stroke were aged more than 70 years [25].

Hypertension was the commonest risk factor for stroke in this study found in $71 \%$ of the cases and $42 \%$ of the controls. It is well established that higher blood pressure levels are potent determinants for stroke, especially ischemic stroke and intracerebral hemorrhage [26]. Similarly, previous works from Kano, Benin-City (south-south Nigeria), Maiduguri and Burkina Faso all revealed a high prevalence of $79 \%, 66 \%, 87 \%$, and $84 \%$ respectively [22] [27]-[29]. Studies done in whites showed a much lower value when compared with blacks ( $52 \%$ in whites vs $76 \%$ in black Africans, $\mathrm{p}<0.001$ ) in a population based study [30]. In addition, McGruder et al. showed that among stroke survivors, blacks were 1.65 times more likely to be hypertensive than whites [31]. Stroke is more common, more severe, and carries a higher mortality among blacks when compared with other races [32]. This is attributed to the fact that blacks have an increased frequency of traditional risk factors for stroke such as diabetes mellitus, hypertension, and obesity [32] [33]. However, management of hypertension with antihypertensive therapy reduces the risk of stroke by about $42 \%$ in the general population [34] [35].

In the present study, DM was found in $13 \%$ of the cases and $6 \%$ of the control group while post stroke hyperglycemia was found in $10 \%$ of the cases. Similarly, Karaye et al. reported a similar prevalence of DM of 14\%, from Kano, while Desulu et al. and Amu et al. reported a higher prevalence of $23.8 \%$ from Ido-Ekitiand $26.25 \%$ from Benin city respectively [22] [25] [27]. However, Watilla et al. and Zabsonre from Maiduguri and Burkina Faso reported a lower prevalence of $8 \%$ and $7.3 \%$ respectively [23] [29]. The 
difference between the findings in the Northern and Southern parts of the country could be probably be explained by differences in dietary habits, coupled with adoption of western lifestyle and possibly genetic factors.

Prospective, community based epidemiologic studies conducted in the United States and Europe suggest that approximately one fifth of stroke patients have DM [39]. Diabetes is an important risk factor for stroke and an independent risk factor for death [37]. It has been noted that diabetes and hypertension have an additive effect on the risk of stroke [38]. DM is a major risk factor for the development of atherosclerosis and the excess risk of stroke in patients with diabetes mellitus is about four times higher when compared with normal individuals in the general population [39]. Hyperglycemia after stroke is common and associated with a poorer outcome [40]. Several studies have found that short and long-term mortality rates and risk of death are higher in stroke patients with admission hyperglycaemia [40]-[42].

Dyslipidemia was significantly higher among the cases (53\%) as compared to the controls (37\%) in the present study. Similarly, reports from the USA showed prevalence of dyslipidemia in stroke patients of 50.7\%, while other studies reported lower rates of $15 \%$ in Maiduguri, and 20.6\% in Burkina Faso [23] [29] [43]. This could be related to a higher cut off value of total cholesterol of $5.5 \mathrm{mmols} / \mathrm{l}$ as compared to $5.2 \mathrm{mmols} / \mathrm{l}$ used in the present study. Furthermore Kano has been described in a National Survey to have the highest burden of hypertension and dyslipidemia in the country [7].

Conversely, lower total cholesterol levels were reported in male stroke patients as compared with healthy controls from Gombe, (Nigeria), while no significant difference between the cases and controls were found in Benin (Nigeria) [27] [44]. The mean HDL cholesterol among the cases was higher than what was obtained among the controls although the difference was not statistically significant. Ephraim et al. and Misirli et al. reported no statistically significant difference in the $\mathrm{HDL}_{\mathrm{C}}$ cholesterol between stroke patients and control subjects [45] [46]. The mean TG and $\mathrm{LDL}_{\mathrm{c}}$ did not differ significantly between the cases and the control group in the present study, in agreement with another study [45]. Similarly a recent study in Calabar (Nigeria) reported no statistical difference in HDLc, LDLc and triglycerides between stroke cases and their controls [46]. The predictive role of lipid profile in stroke is still unclear in spite of the fact that various large randomized trials of statins have established the reduction of stroke risk associated with lowering lipid levels [47]. This might be due to other beneficial effects of statins on the reduction of stroke risk which include stabilization of atherosclerotic plaques, improvement of endothelial function, antioxidant properties, increased nitric oxide bioavailability, inhibition of inflammatory responses and immunomodulatory actions [48].

Although blacks seem to suffer less from AF than Caucasians, consistent with our findings, it is still an important independent risk factor for stroke and a predictor of early recurrence [30] [49]. In a community based study, Hajat et al. reported a prevalence of AF among white subjects as $25 \%$ and $7 \%$ among Blacks $(p=0.001)$ [30]. Our finding was similar to what was reported from India (8\%), but lower than reports from 
Canada (12\%) [50] [51]. Reports from Benin, Southern Nigeria revealed lower prevalence of 5\% among the cases Vs $0 \%$ among the control group, and this could be explained by the low prevalence of heart disease in the Benin study [27]. In the worldwide Inter-stroke study, cardiac causes (of which AF constituted $>50 \%$ ) emerged among the 10 most important risk factors for stroke with a population attributable risk of $6.7 \%$ [52] [53].

Low SES was observed to be a significant risk factor in our study, as previously documented [27]. Low SES is associated with higher incidence of stroke, stroke risk factors, and rates of stroke mortality within and between populations worldwide [54] [55]. TIA appeared to be an important risk factor in this study. Similarly, a Hajat et al. in United Kingdom and Desalu et al. in South Western Nigeria reported prevalence similar to the findings in this study [25] [30]. However lower prevalence was reported from North Eastern Nigeria [23]. Whites have higher prevalence of TIA as compared with blacks [52].

Family history of stroke was significantly higher among the stroke patients as compared to the controls as was previously noted [27]. Sedentary life style was common among the two groups, though the difference between the two groups was not statistically significant $(\mathrm{P}=0.09)$, although lower prevalence was previously reported among stroke patients [27].

Cigarette smoking and alcohol ingestion are uncommon in both study groups. Cigarette smoking was also reported to be insignificant in earlier studies among Nigerians, but a recent study in Benin (Nigeria) revealed that it was a strong risk factor (11.25\% vs 1.25\%) [22] [56] [57]. Smoking promotes atherosclerosis, platelet aggregation and vascular occlusion [23]. The low prevalence of alcohol consumption reflects the different socio-cultural norms of different parts of the country.

The prevalence of HIV infection was low in the present study. HIV is increasingly becoming a known risk factor for stroke in Sub-Saharan Africa where it has been shown to be associated with coagulation abnormalities, such as Protein S deficiency [58] [59]. HIV remained an independent predictor of stroke after adjustment for traditional risk factors as reported by Chow et al. [60]. Hypotheses to explain this excess risk include inflammation, endothelial dysfunction, and macrophage activation [61]. However Mochan et al., found the causes of stroke in HIV-positive stroke patients to be similar to those in HIV negative stroke patients while Watila et al. in Maiduguri (Northeastern Nigeria) and Ezeala et al. from Southeastern Nigeria reported a prevalence of $1.3 \%$ of HIV in stroke cases and $3.4 \%$ in the female stroke cases respectively [9] [23] [62]. This could be explained by the relatively low prevalence of HIV in Nigeria of 3.9\% [63]. However, HIV infection is confirmed to be a risk factor for stroke thus the need for screening of all patients [62].

Heart disease appears to be an important risk factor in this study. HHD was the commonest, followed by IHD and RHD. Similarly, Karaye et al. in a previous study in Kano reported a high prevalence of heart disease (65.4\%) among stroke patients [22]. This contrasts with the finding by Amu et al. in Benin City, who reported a low preva- 
lence in both the cases and controls $(2.5 \%$ vs $0 \%(\mathrm{p}>0.05))$, although the prevalence of hypertension in their study was $85 \%$ [27]. The prevalence of heart disease was found to be lower in the study by Amu et al probably because echocardiography was not used in all the patients [27]. Echocardiography has been shown to have higher sensitivity and specificity than ECG in detecting LVH and other structural cardiac abnormalities [64].

In this study, the other risk factors were uncommon, but should in no way be neglected. One of the strengths of this study is in its case-control design involving a relatively sizeable number of subjects. Some of the limitations of the study include a relatively large percentage of patients not having a brain Computed Tomography or Magnetic Resonance Imaging and other risk factors such as protein C and S deficiency and antiphospholipid antibodies could not be assessed due to cost and non availability. Performing a brain scan for all patients would have increased the strength of the study, by assessing the relationship between risk factors and stroke subtypes.

\section{Conclusion}

This study has demonstrated that the most frequent risk factors for stroke were systemic hypertension, heart diseases, male sex and dyslipidemia, while HIV and other risk factors were uncommon. Community friendly intervention programmes aimed at preventing and modifying the risk factors in persons prone to stroke should be incorporated into the health care system so as to recognise them early and effectively manage them. This study could form a basis for larger population based studies to determine the prevalence of stroke and its associated risk factors.

\section{References}

[1] Mukherjee, D. and Patil, C.G. (2011) Epidemiology and the Global Burden of Stroke. World Neurosurgery, 76, 85-90. http://dx.doi.org/10.1016/j.wneu.2011.07.023

[2] World Health Organization (2012) Facts Sheet on the 10 Leading Causes of Death. Updated 2014. http://www.who.int/mediacentre/factsheets/fs310/en/

[3] Strong, K., Mathers, C.D. and Bonita, R. (2007) Preventing Stroke: Saving Lives around the World. Lancet Neurology, 6, 182-187. http://dx.doi.org/10.1016/S1474-4422(07)70031-5

[4] World Health Organization (2004) Global Burden of Disease (GBD) 2002 Estimates. World Health Report 2004. WHO, Geneva, Switzerland.

[5] Murray, C.J., Ezzati, M., Flaxman, A.D., et al. (2012) GBD 2010: Design, Definitions, and Metrics. The Lancet, 380, 2063-2066. http://dx.doi.org/10.1016/S0140-6736(12)61899-6

[6] Moran, A., Forouzanfar, M., Sampson, U., Chugh, S., Feigin, V. and Mensah, G. (2013) The Epidemiology of Cardiovascular Diseases in Sub-Saharan Africa: The Global Burden of Diseases, Injuries and Risk Factors 2010 Study. Progress in Cardiovascular Diseases, 56, 234-239. http://dx.doi.org/10.1016/j.pcad.2013.09.019

[7] Non-Communicable Diseases in Nigeria (1997) Final Report of a National Survey. Federal Ministry of Health, National Expert Committee on NCD.

[8] World Medical association Declaration of Helsinki (2002) Ethical Principles for Medical research Involving Human Subjects. Journal of Post graduate Medicine, 48, 206-208.

[9] Ezeala-Adikaibe, B.A., Onwekwe, I.O., Ekenze, O.I., Madubuko, K. and Ofoegbu, E.N. 
(2010). Stroke Risk Factor Profile in Nigerian African Women. Internet Journal of Neurology, 13, No. 1.

[10] Aho, K., Harmsen, P., Hatano, S., Marquardsen, J., Smirnov, V. and Strasser, T. (1980) CVD in the Community: Results of a WHO Collaborative Study. Bull World Health Organisation, 58, 113-130.

[11] Qureshi, A.I., Janssen, R.S., Karon, J.M., Weissman, J.P., Akbar, M.S., Safdar, K. and Frankel, M.R. (1997) Human Immunodeficiency Virus Infection and Stroke in Young Patients. Archives of Neurology, 54, 1150-1153. http://dx.doi.org/10.1001/archneur.1997.00550210078016

[12] WHO MONICA Project Principal Investigators (1988) The World Health Organization MONICA Project (Monitoring Trends and Determinants in Cardiovascular Disease): A Major International Collaboration. Journal of Clinical Epidemiology, 41, 171-184.

[13] World Health Organization (1999) International Society of Hypertension Guidelines for the Management of Hypertension. Blood Pressure, 8, 3-43.

[14] World Health Organization (1999) Definition, Diagnosis and Classification of Diabetes Mellitus and Its Complications; Report of a WHO Consultation Part 1; Diagnosis and Classification of Diabetes Mellitus Geneva. World Health Organization.

[15] Scott, J.F., Robinson, G.M., French, J.M., O’Connell, J.E., Alberti, K.G. and Gray, C.S. (1999) Prevalence of Admission Hyperglycemia across Clinical Subtypes of Acute Stroke. The Lancet, 353, 376-377. http://dx.doi.org/10.1016/S0140-6736(05)74948-5

[16] National Cholesterol Education Program (2002) Third Report of the Expert Panel on the Detection, Evaluation and Treatment of High Blood Cholesterol in Adults (Adult Treatment Panel III). National Heart Lung and Blood Institute.

[17] Barker, J., Cryer, C. and Maryon-Davis, A. (1993) Health Quest South East: Regional Report. South Thames Regional Health Authority.

[18] Karaye, K.M., Okeahialam, B.S. and Wali, S.S. (2007) Cardiovascular Risk factors In Nigerians with Systemic Hypertension. Nigerian Journal of Medicine, 16, 2.

http://dx.doi.org/10.4314/njm.v16i2.37293

[19] Douglas, P.S., Garcia, M.J., Haines, D.E., Lai, W.W., Manning, W.J., Patel, A.R., et al. (2011) ACCF/ASE/AHA/ASNC/HFSA/HRS/SCAI/SCCM/SCCT/SCMR 2011 Appropriate Use Criteria for Echocardiography. A Report of the American College of Cardiology Foundation Appropriate Use Criteria Task Force, American Society of Echocardiography, American Heart Association, American Society of Nuclear Cardiology, Heart failure Society of America, Heart Rhythm Society, Society for Cardiovascular Angiography and Interventions, Society of Critical Care Medicine, Society of Cardiovascular Computed Tomography, Society for Cardiovascular Magnetic Resonance American College of Chest Physicians. Journal of American Society of Echocardiography, 24, 229-67.

[20] Schiant, R.C., Adolph, R.J., Dimarco, J.P., et al. (1992) Guidelines for Electrocardiography. A Report of the ACC/AHA Task Force on Assessment of Diagnostic and Therapeutic Cardiovascular Procedures (Committee on Electrocardiography). Journal of American College of Cardiology, 19, 473.

[21] Ogun, S.A., Oluwole, O., Fatade, B., Ogunseyinde, A.O., Ojini, F.I. and Odusote, K.A. (2002) Comparison of Siriraj Stroke Score and the WHO Criteria in the Clinical Classification of Stroke Subtypes. African Journal of Medicine and Medical Sciences, 31, 13-16.

[22] Karaye, K.M., Nashabaru, I., Fika, G.M., Ibrahim, D.A., Maiyaki, B.M. and Ishaq, N.A., et al. (2007) Prevalence of Traditional Cardiovascular Risk Factors among Nigerians with Stroke. Cardiovascular Journal of African, 18, 290-294.

[23] Watila, M.M., Nyandaiti, Y.W., Ibrahim, A., Balarabe, S.A., Gezawa, I.D., Bakki, B., et al. 
(2012) Risk Factor Profile among Black Stroke Patients in Northeastern Nigeria. Journal of Neuroscience and Behavioural Health, 4, 50-58. http://dx.doi.org/10.5897/JNBH11.052

[24] De Abreu, T.T., Mateus, S. and Correia, J. (2005) Therapy Implications of Transthoracic Echocardiography in Acute Ischemic Stroke Patients. Stroke, 36, 1565-1566. http://dx.doi.org/10.1161/01.STR.0000170636.08554.49

[25] Desalu, O.O., Wahab, K.W., Fawale, B., Olarenwaju, T.O., Busari, O.A., Adekoya, A.O., et al. (2011) A Review of Stroke Admissions at a Tertiary Hospital in Rural Southwestern Nigeria. Annual of African Medicine, 10, 80-85. http://dx.doi.org/10.4103/1596-3519.82061

[26] Gezmu, T. (2012) Racial/Ethnic Variation in Acute Stroke. A Registry Based Multi-Ethnic Study in New Jersey. Rutgers University Community Repository.

[27] Amu, E., Ogunrin, O. and Danesi, M. (2005) Re-Appraisal of Risk Factors for Stroke in Nigerian Africans-A Prospective Case-Control Study. African Journal of Neurological Sciences, 24, 20-27.

[28] Bwala, S.A. (1989) Stroke in a Sub-Saharan Nigerian Hospital-A Retrospective Study. Tropical Doctor, 19, 11-14.

[29] Zabsonre, P., Yameogo, A., Millogo, A., Dyemkouma, F.X., Durand, G., et al. (1997) Risk and Severity Factors between Cerebrovascular Accidents in West African Blacks of Burkina Faso. Medecine Tropicale, 57, 147-152.

[30] Hajat, C., Dundas, R., Stewart, J.A., Lawrence, E., Rudd, A.G., Howard, R. and Wolfe, C.D.A. (2001) Cerebrovascular Risk Factors and Stroke Subtypes Differences between Ethnic Groups. Stroke, 32, 37-42. http://dx.doi.org/10.1161/01.STR.32.1.37

[31] McGruder, H.F., Malarcher, A.M., Antoine, T.L., Greenlund, K.J. and Croft, J.B. (1999) Racial and Ethnic Disparities in Cardiovascular Risk Factors among Stroke Survivors United States 1999 to 2001. Stroke, 35, 1557-1561. http://dx.doi.org/10.1161/01.STR.0000130427.84114.50

[32] Jones, M.R., Horner, R.D., Edwards, L.J., Hoff, J., Armstrong, S.B., Smith-Hammond, C.A., Matchar, D.B. and Oddone, E.Z. (2000) Racial Variation in Initial Stroke Severity. Stroke, 31, 563-567. http://dx.doi.org/10.1161/01.STR.31.3.563

[33] Imam, I. (2002) Stroke: A Review with an African Perspective. Annals of Tropical Medicine and Parasitology, 96, 435-445. http://dx.doi.org/10.1179/000349802125001276

[34] Bronner, L.L., Kanter, D.S. and Manson, J.E. (1995) Primary Prevention of Stroke. New England Journal of Medicine, 23, 1392-1400. http://dx.doi.org/10.1056/NEJM199511233332106

[35] MacMahon, S. and Rogers, A. (1994) Epidemiological Association between Blood Pressure and Stroke. Implication for Primary and Secondary Prevention. Hypertension Research, 17, 523-532. http://dx.doi.org/10.1291/hypres.17.SupplementI_S23

[36] Jorgensen, H., Nakayama, H., Raaschou, H.O. and Olsen, T.S. (1994) The Copenhagen Stroke Study. Stroke in Patients with Diabetes. Stroke, 25, 1977-1984. http://dx.doi.org/10.1161/01.STR.25.10.1977

[37] Tuomilehto, J., Rastenyte, D., Jousilahti, P., Sarti, C. and Vartiainen, E. (1996) Diabetes Mellitus as a Risk Factor for Death from Stroke. Prospective Study of the Middle-Aged Finnish Population. Stroke, 27, 210-215. http://dx.doi.org/10.1161/01.STR.27.2.210

[38] Hu, G., Sarti, C., Jousilahti, P., Peltonen, M., Qiao, Q., Antikainen, R. and Tuomilehto, J. (2005) The Impact of History of Hypertension and Type 2 Diabetes at Baseline on the Incidence of Stroke and Stroke Mortality. Stroke, 36, 2538-2543. http://dx.doi.org/10.1161/01.STR.0000190894.30964.75

[39] Hasan, S.R. and Khan, G.A. (2007) Frequency of Known Risk Factors of Stroke and Its 
Outcome in Patients Admited in Smith Government Qatar Hospital Karachi. Pakistan Journal of Medical Sciences, 23, 634-636.

[40] Williams, L.S., Rotich, J., Qi, R., Fineberg, N., Espay, A., Bruno, A., Fineberg, S.E. and Tierney, W.A. (2002) Effects of Admission Hyperglycemia on Stroke Mortality and Costs in Acute Ischemic Stroke. Neurology, 59, 67-71. http://dx.doi.org/10.1212/WNL.59.1.67

[41] Weir, C.J., Murray, G.D., Dyker, A.G. and Lees, K.R. (1997) Is Hyperglycaemia an Independent Predictor of Poor Outcome after Acute Stroke? Results of a Long-Term Follow up Study. British Medical Journal, 314, 1303-1306. http://dx.doi.org/10.1136/bmj.314.7090.1303

[42] Wahab, K., Okubadejo, N., Ojini, F. and Danesi, M. (2007) Effect of Admission Hyperglycemia on Short Term Outcome in Adults Nigerians with a First Acute Ischemic Stroke. African Journal of Neurological Sciences, 26, 48-57.

[43] Smith, E.E., Abdullah, A.R., Amirfarzan, H. and Schwamm, L.H. (2007) Serum Lipid Profile on Admission for Ischemic Stroke. Failure to Meet National Cholesterol Education Program Adult Treatment Panel (NCEP-ATP) III Guidelines. Neurology, 68, 660-665. http://dx.doi.org/10.1212/01.wnl.0000255941.03761.dc

[44] Glew, H.R., Okolie, H., Crossey, M., Suberu, O., Trujillo, M., Pereyra Dorothy, J., et al. (2004) Serum Lipid Profiles and Homocysteine Levels in Adults with Stroke or Myocardial Infarction in the Town of Gombe in Northern Nigeria. Journal of Health Population and Nutrition, 22, 341-347.

[45] Misirli, H., Somay, G., Ozbal, N. and Yasar-Erenoglu, N. (2002) Relation of Lipoprotein(a) to Ischaemic Stroke. Journal of Clinical Neurosciences, 9, 127-132. http://dx.doi.org/10.1054/jocn.2001.1030

[46] Philip-Ephraim, E.E., Charidimou, A., Williams, U.E., Out, A.A., Eyong, K.I. and Ephraim, R.P. (2015) Serum Lipid Profile in Ischaemic Stroke Patients in Southern Nigeria. Journal of Dental and Medical Sciences, 14, 2279-0861.

[47] Taylor, W.C. and Landau, W.M. (1990) Atherosclerosis and Stroke. Annals of Neurology, 28, 108. http://dx.doi.org/10.1002/ana.410280122

[48] Endres, M. (2005) Statins and Stroke. Journal of Cerebral Blood Flow and Metabolism, 25, 1093-1110. http://dx.doi.org/10.1038/sj.jcbfm.9600116

[49] Moroney, J.T., Bagiella, E., Paik, M.C., Sacco, R.L. and Desmond, D.W. (1998) Risk Factors for Early Recurrence after Ischemic Stroke: The Role of Stroke Syndrome and Subtype. Stroke, 29, 2118-2124. http://dx.doi.org/10.1161/01.STR.29.10.2118

[50] Simons, L.A., McCallum, J., Friedlander, Y. and Simons, J. (1998) Risk Factors for Ischemic Stroke: Dubbo Study of the Elderly. Stroke, 29, 1341-1346. http://dx.doi.org/10.1161/01.STR.29.7.1341

[51] Rem, J.A., Hachinski, V.C., Boughner, D.R. and Barnett, H.J. (1985) Value of Cardiac Monitoring and Echocardiography in TIA and Stroke Patients. Stroke, 16, 950-956. http://dx.doi.org/10.1161/01.STR.16.6.950

[52] Albers, G.W., Amarenco, P., Easton, J., Sacco, R.L. and Teal, P. (2001) Antithrombotic and Thrombolytic Therapy for Ischemic Stroke. Chest, 119, 300S-320S. http://dx.doi.org/10.1378/chest.119.1_suppl.300S

[53] O’Donnell, M., Xavier, D., Liu, L. and Yusuf, S. (2010) Interstroke Investigators. Risk Factors for Ischemic and Intracerebral Hemorrhagic Stroke in 22 Countries (The Interstroke Study): A Case Control Study. Lancet, 376, 112-123. http://dx.doi.org/10.1016/S0140-6736(10)60834-3

[54] Addo, J., Ayerbe, L., Mohan, K.M., Crichton, S., Sheldenkar, A., Chen, R., et al. (2012) So- 
cioeconomic Status and Stroke. An Updated Review. Stroke, 43, 1186-1191. http://dx.doi.org/10.1161/STROKEAHA.111.639732

[55] Sacco, R.L., Roberts, K.J., Boden-Albala, B., Gu, Q. and Lin, I.F. (1997) Race-Ethnicity and Determinants of Carotid Atherosclerosis in a Multiethnic Population: The Northern Manhattan Stroke Study. Stroke, 28, 929-935. http://dx.doi.org/10.1161/01.STR.28.5.929

[56] Osuntokun, B.O., Bademosi, O., Akinkugbe, O.O., Oyediran, A. and Carlisle, R. (1979) Incidence of Stroke in an African City: Results from the Stroke Registry at Ibadan, Nigeria, 1973-1975. Stroke, 10, 205-207. http://dx.doi.org/10.1161/01.STR.10.2.205

[57] Ogunrin, O.A. and Unuigbe, E. (2008) Serum Lipids in Patients with Stroke: A Cross-Sectional Case-Control Study. Journal of the National Medical Association, 100, 986-990. http://dx.doi.org/10.1016/S0027-9684(15)31433-4

[58] AIDS Patients (2000) Observations from the Edinburgh HIV Autopsy Cohort. Stroke, 31, 2117-2126. http://dx.doi.org/10.1161/01.STR.31.9.2117

[59] Mochan, A., Modi, M. and Modi, G. (2003) Stroke in Black South African HIV-Positive Patients: A Prospective Analysis. Stroke, 34, 10-15. http://dx.doi.org/10.1161/01.STR.0000043821.35051.FA

[60] Chow, F.C., Regan, S., Feske, S., Meigs, J.B., Grinspoon, S.K. and Triant, V.A. (2012) Comparison of Ischemic Stroke Incidence in HIV-Infected and Non-HIV-Infected Patients in a US Health Care System. Journal of Acquired Immune Deficiency Syndrome, 60, 351- 358. http://dx.doi.org/10.1097/QAI.0b013e31825c7f24

[61] Cole, J.W., Pinto, A.N., Hebel, J.R., Buchholz, D.W., Earley, C.J., Johnson, C.J., et al. (2004) Acquired Immunodeficiency Syndrome and the Risk of Stroke. Stroke, 35, 51-56. http://dx.doi.org/10.1161/01.STR.0000105393.57853.11

[62] Prevalence of Stroke in Nigeria (2008) 2008 Country Profile: Nigeria. US Department of State.

[63] Nigeria UNGASS Report 2007 (2008) National Agency for Control of AIDs, Nigeria.

[64] Surawicz, B. (1986) Electrocardiographic Diagnosis of Chamber Enlargement. Journal of the American College of Cardiology, 8, 711-724. http://dx.doi.org/10.1016/S0735-1097(86)80207-8

\section{Submit or recommend next manuscript to SCIRP and we will provide best service} for you:

Accepting pre-submission inquiries through Email, Facebook, LinkedIn, Twitter, etc. A wide selection of journals (inclusive of 9 subjects, more than 200 journals)

Providing 24-hour high-quality service

User-friendly online submission system

Fair and swift peer-review system

Efficient typesetting and proofreading procedure

Display of the result of downloads and visits, as well as the number of cited articles

Maximum dissemination of your research work

Submit your manuscript at: http://papersubmission.scirp.org/

Or contactwjcs@scirp.org 